JIANG HAIBO

JINJIN

and

QIN ZHIPENG

\title{
Analysis on water migration in freeze-thaw process of composite lining canal in seasonal frozen soil area
}

In order to quantify the migration rule of water in composite lining canal foundation soil during the freeze-thaw process, the outdoor prototype test is performed to prove the change rules of water in different positions and depths of the rigidflexible mixed composite lining canal foundation during the whole freeze-thaw cycle. The prototype observation test shows that during the freezing period, the water content within the $0 \sim 80 \mathrm{~cm}$ depth of the canal foundation soil increases with the depth, and that within the depth of $80 \sim 160 \mathrm{~cm}$ decreases gradually with the depth. In the freezing period, water accumulates in the depth of $60 \sim$ $80 \mathrm{~cm}$, with a maximum water transfer amount of $+13.2 \%$, which occurs at the canal bottom. In the thawing period, the maximum water content also occurs at the canal bottom, with a maximum water transfer amount of $-11.0 \%$. Through the laboratory test of soil samples, the water migration development and change rules of the canal foundation soil, under different moisture contents and temperature gradients are studied in unilateral pattern. In the case of the same top plate control temperature, soil samples with similar initial water contents have similar water transfer amounts. The samples with higher initial water content have higher water transfer amount, with higher water accumulation, normally accumulating in the depth of $16 \sim 18 \mathrm{~cm}$. The results indicate that high water contents make it easy to gather water in soil samples during the freezing period.

Keywords: Composite lining canal, freeze-thaw test, water migration, water accumulation

\subsection{Introduction}

$\mathrm{E}$ arly in the 17th century, the phenomenon of soil frost heaving was noticed, but until the 20th century, people began to realize that water migration is the main reason resulting in soil frost heaving [1]. In 1961, Everett proposed No.1 Frost Heave Theory through tests, namely the Capillary Theory [2]. In a sense, it gave the explanations of the motive power for water migration. But later tests found the existence of frozen fringe and the important role it plays

Messrs. Jiang Haibo, JinJin, and Qin Zhipeng, Water Conservancy and Architectural Engineering College of Shihezi University, Shihezi City, Xinjiang Province, China. as the passageway for water migration, and such phenomenon as non-continuous ice lens generation and growth, etc., which proved the limitations of No.1 Frost Heave Theory. Recognizing the shortage of the Capillary Theory, in 1972, Miller proposed that there existed a zone with low water content, low moisture conductivity and without frost heaving at the freezing front and warmest ice lens bottom surface, known as the Frozen Fringe [3]. The frozen fringe theory overcomes the shortcomings of the Capillary Theory, called No.2 Frost Heave Theory.

Among the studies on water migration during soil frost heaving-thawing-settlement process, some existing theories on water migration in freeze-thaw soil can explain the observed phenomena [4-17]. During or after freezing, the water migration phenomenon in soil has been noticed because it has changed the phase transition of water in the soil as well as the microstructure and properties of soil in varying degrees [6], and also the resulting stress and displacement intensity and velocity [10]. For example, during soil freezing process, with the invasion of the freezing front, water in the soil is redistributed, which leads to soil water content exceeding the original pore volume in certain depth, accumulating into single ice lens or regularly distributed ice lens along the depth direction. Thus, great frost heave pressure or constraint reaction force is formed [9], which causes the displacement of soil parent rock and non-soil materials in the soil (such as plant roots, pipelines and building foundation), resulting in freezing damage. Excessive frost heave will cause the inhomogeneous deformation of the ground, and may result in the damages to surrounding environment such as the upper or the adjacent buildings and structure foundation even gas, electricity, communication and drainage pipelines and lines, affecting the success or failure of a project and causing huge economic losses and social impacts.

Frost heave and thaw settlement of the soil in the seasonal frozen areas will cause damage in varying degrees to the canal lining structure. Existing 50\% buildings, $45 \%$ canal structures and $34 \%$ lining canals have suffered from frost heaving destruction. From the point of view of canal frost heave mechanism [18], frost heave will occur under such 
three basic conditions: canal foundation soil is frost heaving soil, there is a continuous negative temperature, and water content is higher than that of the initial frost heaving of foundation soil [19]. As long as one of the three factors is controlled in a certain level, the occurrence of frost heave of the canal can be prevented [20]. As to the patterns of the frost heave damage to the rigid lining canal, the main damage patterns include lining structure's swelling and cracking, heaving and suspending, overall uplifting, slab dislocation, or even lining break or collapse in serious cases, which means that the rigid lining masonry cannot effectively adapt to and eliminate frost heave deformation. The unfrozen water content of sodium sulfate saline soils with high salt content decreases exponentially, and the water content no longer changes when the temperature of soils is up to -10 !. For the sodium sulfate saline soils with low salt content, the unfrozen water content also decreases exponentially, and under the same temperature, the unfrozen water content of soils increases as the salt content increases [21].

But so far, the theory and model for water migration characteristics of the canal foundation under seasonal freezethaw conditions have not been established yet. Currently, the anti-frost heave design of canals is mainly based on the principles of "adaptation, avoidance and prevention of frost heave", with such engineering measures as anti-frost heave structures, heat insulation materials, anti-seepage and drainage, foundation soil replacement, etc. being taken to achieve the purpose of "adaptation and prevention of frost heave damage”. During 1991 2004, China successively promulgated three codes on the canal field, but the effects of seasonal freeze-thaw on water migration of canal foundation soil, etc. are not included. Therefore, in order to quantify the migration of water in composite lining canal foundation soil, this paper, based on outdoor prototype observation tests, proved the change rules of water in different positions and depths of rigid-flexible mixed composite lining canal foundation during the whole freezing-thawing cycle. Through laboratory tests, the water migration development and change rules in unilateral freezing pattern, under different temperature gradients for soils with different structures and silty clays with different water contents were studied, which provides a theoretical basis for the design, popularization and application of rigid-flexible mixed composite lining canal in seasonal frozen soil region.

\subsection{Prototype observation test for water migration during freezing process}

\subsection{BASIC INFORMATION OF THE TEST SECTION}

The prototype observation test region is located in a large irrigation district in Fukang, Xinjiang autonomous region in northwest of China. The region has a maximum average frozen soil depth of $1.45 \mathrm{~m}$, and a measured annual maximum frozen depth of $1.72 \mathrm{~m}$, belonging to seasonal frozen soil region. According to the soil test data, the mass of canal foundation soil with the particle size smaller than $0.075 \mathrm{~mm}$ is over $10 \%$ of the total mass, which belongs to the frost heave soil. The yearly average temperature of the test area is 6.5 ! and the extreme minimum temperature is $-25^{\circ} \mathrm{C} \sim-32.2^{\circ} \mathrm{C}$.

The test section of the canal has a length of $20 \mathrm{~m}$, which is a trapezoidal semi-filling and semi-excavation rigid-flexible composite lining canal, with a bottom width of $4.0 \mathrm{~m}$, canal depth of $3.0 \mathrm{~m}$, side slope of 1:1.5 and longitudinal slope of $1 / 300$. According to the soil test results, the canal foundation soil has a water content of $16 \% \sim 23 \%$, density of $1.51 \sim 1.65 \mathrm{~g} /$ $\mathrm{cm}^{3}$, porosity of $0.69 \sim 0.80$ (belonging to low liquid limit silt), plasticity index of $5.8 \sim 6.4$, liquid index of $0.53 \sim 0.82$, permeability coefficient of $2.25 \times 10^{-4} \sim 8.49 \times 10^{-4} \mathrm{~cm} / \mathrm{s}$, compression coefficient of $0.25 \sim 0.31 \mathrm{MPa}^{-1}$, compression modulus of $6.0 \sim 7.3 \mathrm{MPa}$ (belonging to medium compressibility), cohesion of $6.2 \sim 11.6 \mathrm{kPa}$, and internal friction angle of $16.5^{\circ} \sim 22.3^{\circ}$. The ground water locates $10 \mathrm{~m}$ under the canal bottom.

\subsection{DESIGN, OBSERVATION FACILITY ARRANGEMENT AND OBSERVATION METHODS FOR THE TEST SECTION}

Under the premise of keeping the original soil canal water surface elevation and canal's longitudinal gradient unchanged, the canal test section is lined with rigid-flexible mixed composite lining structure $(12 \mathrm{~cm}$-thick rigid concrete lining plate + flexible composite geo-membrane). According to the stable soil canal foundation and monitoring on existing projects, the canal composite concrete lining slabs are equal thickness slabs, with the thickness of $12 \mathrm{~cm}$. The flexible composite geo-membrane is laid on canal slope slabs and bottom slabs, with the composite lining structure of cast-inplace concrete slab + flexible composite geo-membrane. The canal side slope is rammed compact by breaststroke ramming machine, with a controlled dry density of over $1.6 \mathrm{~g} / \mathrm{cm}^{3}$. The canal has a design flow rate of $21 \mathrm{~m}^{3} / \mathrm{s}$, maximum flow rate of $26 \mathrm{~m}^{3} / \mathrm{s}$. Fig. 1 shows the cross section of the rigid-flexible mixed composite lining canal.

Before the test was commenced, the test section of the composite lining canal was running under the design water level, so that the test section can reach the actual situation of the canal. The longitudinal layout and plane layout of the observation points are shown in Fig.1. The length of canal foundation soil for water observation is $20 \mathrm{~m}$. Three observation points denoted by A, B, C, respectively are arranged on the sunny slope; one observation point $\mathrm{D}$ is arranged at the canal bottom; another three observation points denoted by E, F, G, respectively are arranged on the shady slope. For quantitative analysis of water change rules in different positions and depths of the rigid-flexible mixed composite lining canal foundation, soil drill was used to take soil samples at different depths within $0 \sim 160 \mathrm{~cm}$ under the composite lining structure, and the soil sampling positions are shown in Fig.1. For each observation point, one soil sample was taken at every $20 \mathrm{~cm}$ depth, using drying method 

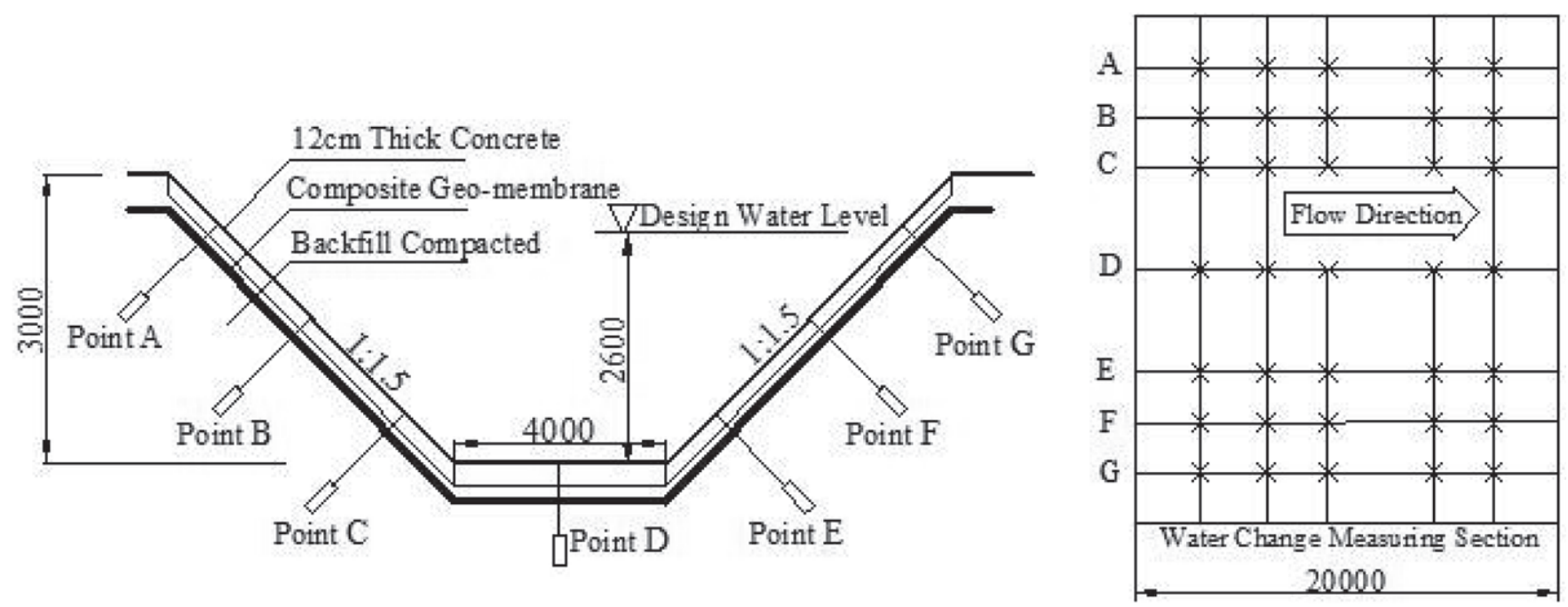

Fig.1 Cross section of trapezoidal canal with concrete and composite geo-membrane and plane lyout of observation points (Unit: mm)

to measure the soil water content. Through comparison with the initial water content, the water transfer amount at each observation point was analyzed. The groundwater level in the test area is over $10 \mathrm{~m}$, and there is no groundwater recharge, so the water change in the freezing period is only the initial water content of the canal foundation soil. After each measurement, local soil was used for backfill. In order to make the measured water content results as close as possible to the actual situation, the next sampling point should have a distance of $30-50 \mathrm{~cm}$ from the last sampling point.

\subsection{ANALYSIS ON PROTOTYPE OBSERVATION RESULTS}

According to the prototype test design, through the prototype observation on the complete freeze-thaw cycle of 140 days (November 5th, 2013 to March 28th, 2014), a prototype test of a complete freeze-thaw cycle was completed. The test focused mainly on the monitoring of water transfer amount at different positions and depths of composite lining canal foundation soil. Fig. 2 shows the variation trend of the water content with the depth at different observation points of composite lining canal during the freezing period. From Fig.2, it can be seen that the variation trend of water content with depth at different observation points is the same; the water content of canal foundation soil in the depth of $0 \sim 80 \mathrm{~cm}$ increases with the depth; but the water content in the depth of $80 \sim 160 \mathrm{~cm}$ decreases with the depth; and water accumulates in the depth of $60 \sim 80 \mathrm{~cm}$.

In order to analyze the water migration amount during the freezing period and thawing period, soil samples were taken in the depth of $0 \sim 160 \mathrm{~cm}$ of the canal foundation, adopting drying method to measure the soil water content. The measured results were compared to the soil initial water content, and the water migration amount at different observation points was calculated. The initial water contents of different observation points are shown in Fig.2. We can see that water accumulates in a $60 \sim 80 \mathrm{~cm}$-deep soil layer during the freezing period. After calculation, the water transfer amount is $+13.2 \%$, which occurs at the bottom of the canal; and in the thawing period, the water transfer amount is $-11.0 \%$, which also occurs at the bottom of the canal.

Fig. 2 shows how water migrates in canal foundation soil under different temperature gradients and water contents at each observation point of a rigid-flexible mixed composite lining canal. Within a freeze-thaw cycle, the water migration amount at the canal bottom is relatively higher. It is $13.2 \%$ during the freezing period and $11.0 \%$ during the thawing period. The same water migration rules are applied to canal sunny and shady slopes during both freezing and thawing periods. The water migration amount goes up as the soil depth increases during the freezing period. The peak amount for the sunny slope is $3.3 \%$ at its $\mathrm{C}$ point, which is near the canal bottom. The peak amount for the shady slope is $3.5 \%$ at its $\mathrm{E}$ point, which is also near the canal bottom. The results suggest that water gradually gathers to the canal bottom during the freezing period.

\subsection{Laboratory water migration test for freeze-thaw cycle}

\subsection{TEST SCHEME DESIGN AND TEST INSTRUMENT}

According to the observation results and relevant literatures, the temperature gradient and initial water content are the two most prominent factors affecting the migration of soil water during the freeze-thaw cycle [21]. In the soil freezing process, frost heave often occurs in the moisture-bearing soil layer, and water migration during the soil frost heaving process is just its movement in form of unfrozen water or film water under the action of temperature gradient. The greater the temperature gradient in the soil is, the faster is the water transfer rate; the larger the initial water content is, the larger will be the water transfer amount and more and more water will accumulate on the freezing front [22].

According to above analysis, the laboratory tests focus 

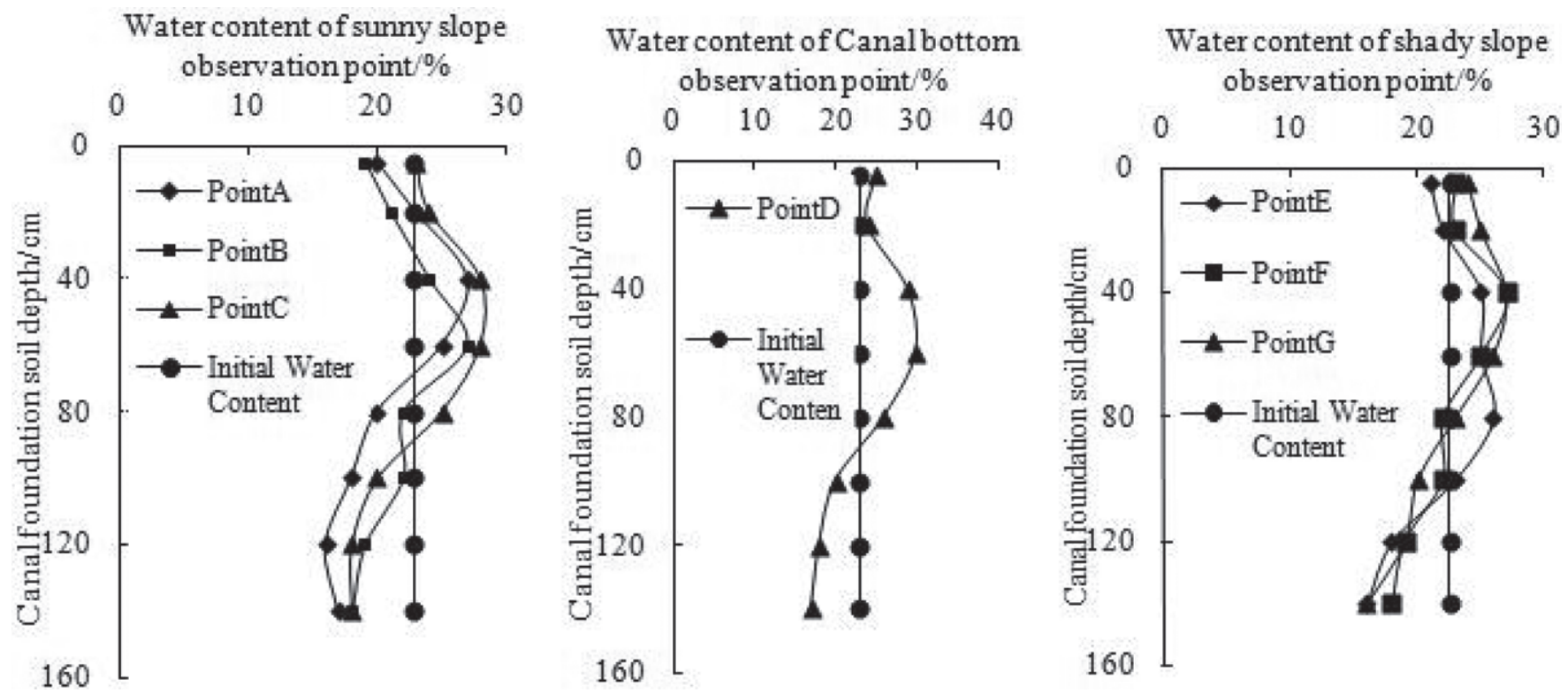

Fig.2 Variation of soil water content with depth during the freezing period of different points

mainly on studying the water migration rules of soil samples during freeze-thaw process under following two cases:

1. Under the same temperature conditions, canal foundation soil samples with different initial water contents were provided with freeze-thaw tests, so as to monitor the change rules and change values of canal soil water content during the freeze-thaw process;

2. Under different temperature conditions, composite lining canal soil samples at different positions with different water contents were provided with the freeze-thaw tests, so as to monitor the change rules and change values of canal soil water content during the freeze-thaw process.

The soil samples for freeze-thaw tests were taken from $0 \sim 3 \mathrm{~m}$-deep soil layer of the prototype observation canal on the sunny slope, shady slope and at the canal bottom, respectively. The cylinder soil samples were prepared in accordance with provisions of "standard for soil test method" (GB/T50123-1999), with a height of $28 \mathrm{~cm}$ and diameter of $10 \mathrm{~cm}$.

For the freeze-thaw test, three groups of samples taken from the composite lining canal foundation were tested, and 9 samples were taken from the shady slope, sunny slope and canal bottom, 3 for each position, respectively. The freezethaw cycle box used for the laboratory tests is a Xutemp's XT5405B series soil frost heave test box, with the composite programming ability of sinusoidal and linear (including constant temperature) rules, suitable for freeze-thaw cycle tests of soil (frozen soil) within the temperature range of $-40^{\circ} \mathrm{C}-+60^{\circ} \mathrm{C}$. The test box is also equipped with air cooling and water cooling systems, having such functions as advanced ultra-temperature protection and abnormal temperature sensing protection, as well as power failure protection memory, etc., which can ensure the continuity and stability of the tests.
Soil water content under different conditions was determined by the drying method. For the quantitative analysis of water change of the canal foundation soil samples during the freeze-thaw process, the soil water content was measured at an interval of $2 \mathrm{~cm}$ for different test requirements. The test conditions are designed as shown in Table 1. Totally, 9 samples were chosen for the tests, 3 temperature patterns were established, and the water migration tests for 9 kinds of initial water contents were performed.

\subsection{TEST METHODS AND PROCEDURES}

The laboratory test methods and procedures are described as below:

1. Freezing test. First, the test sample is installed, ensuring that the test sample can either have the unilateral freeze or unilateral thaw. A constant temperature treatment was provided before freezing, and the temperature of the regulating box is $+6^{\circ} \mathrm{C}$, kept constant for $10 \mathrm{hr}$ to make the temperature inside the sample reach $+6^{\circ} \mathrm{C}$. Then, set the temperature of the freeze-thaw cycle test box so that the box temperature is $+1^{\circ} \mathrm{C}$, so as to reduce the side heat radiation. The bottom plate temperature was also controlled at $+1^{\circ} \mathrm{C}$. The temperature should be strictly controlled, ensuring that the soil samples freeze or thaw only from the top end. Finally, the heat insulation material was wrapped around the sample tube, and then the freezing test was performed after negative temperature was applied to the top of the sample.

2. Thawing test. After complete freezing, the temperature of the top plate was adjusted to the required constant temperature $\left(+6^{\circ} \mathrm{C},+8^{\circ} \mathrm{C}\right.$ and $+10^{\circ} \mathrm{C}$, respectively), and the temperatures of the box body and bottom plate were kept constant. The unilateral thawing test was performed. When the set thawing temperature was reached, stopped 
TABLE 1: TEST CONDITIONS FOR WATER MIGRATION IN SOIL SAMPLES OF CANAL WITH COMPOSITE LINING STRUCTURE

\begin{tabular}{|c|c|c|c|c|c|c|}
\hline \multirow{2}{*}{$\begin{array}{l}\text { Soil sample } \\
\text { group no. }\end{array}$} & \multirow{2}{*}{$\begin{array}{c}\text { Soil sample } \\
\text { no. }\end{array}$} & \multirow{2}{*}{$\begin{array}{l}\text { Sampling } \\
\text { position }\end{array}$} & \multicolumn{2}{|c|}{ Top plate temperature $/{ }^{\circ} \mathrm{C}$} & \multirow{2}{*}{$\begin{array}{c}\text { Initial water } \\
\text { content/ } \%\end{array}$} & \multirow{2}{*}{$\begin{array}{c}\text { Dry } \\
\text { density } / \mathrm{g} / \mathrm{cm}^{3}\end{array}$} \\
\hline & & & Freezing & Thawing & & \\
\hline \multirow[t]{3}{*}{ Group 1} & 1 & Shady slope & -20 & +6 & 22.67 & 1.58 \\
\hline & 2 & & & & 22.58 & 1.53 \\
\hline & 3 & & & & 21.73 & 1.57 \\
\hline \multirow[t]{3}{*}{ Group 2} & 4 & Canal bottom & -20 & +8 & 23.79 & 1.59 \\
\hline & 5 & & & & 23.15 & 1.61 \\
\hline & 6 & & & & 23.41 & 1.57 \\
\hline \multirow[t]{3}{*}{ Group 3} & 7 & Sunny slope & -20 & +10 & 21.67 & 1.53 \\
\hline & 8 & & & & 22.15 & 1.60 \\
\hline & 9 & & & & 21.83 & 1.54 \\
\hline
\end{tabular}

Notes: Before freezing, there is no constant temperature process, the starting temperature is the room temperature. At the beginning of freezing, the top plate has a temperature dropping process, and when it starts to thaw, the top plate has a temperature rise process. Temperature of the bottom plate and the box body is maintained at $+1^{\circ} \mathrm{C}$ in the freeze-thaw process.

the thawing and took out the soil sample to measure the water content layer by layer. To ensure that the sample only freeze or thaw from the top, the top plate temperature change was controlled so that the sample will freeze or thaw up-down.

3. Data acquisition: Upon completion of the freezing and thawing tests, take out the samples and cut into $2 \mathrm{~cm}$ thick slice. Use the drying method to measure the water content of soil sample at different depths.

\subsection{ANALYSIS ON TEST RESULTS}

Considering the effects of different temperature patterns and different water contents on the water migration during the freeze-thaw process, totally 9 groups of soil samples taken from composite lining canal foundation were tested in the laboratory, with 9 samples taken from the shady slope, sunny slope and canal bottom, 3 for each position, for the freezethaw tests. Through testing, relevant test data were obtained, and the test phenomena and test data are analyzed and discussed in detail.

Under the conditions of same top plate temperature and different initial water contents, the initial water content of the samples was uniform. For the given freezing process, the top plate temperature was $-20^{\circ} \mathrm{C}$, the thawing temperature was $6^{\circ} \mathrm{C}, 8^{\circ} \mathrm{C}$ and $10^{\circ} \mathrm{C}$, respectively. Figs.3, 4 and 5 are the variation curves of water content along the depth of different samples at different positions.

From Figs.3, 4 and 5, it can be seen that the variation trend of the water content distribution curves of soil samples at different observation points and different positions is the same. While the water content of the upper soil layer of the sample is increased, it decreased in the lower part. The soil sample has the higher water content in the depth of $16 \sim 18 \mathrm{~cm}$, where water accumulation occurs, which is consistent with the phenomenon observed during the canal prototype test. Under the same top plate temperature, when the sample has higher initial water content, the water transfer amount is also

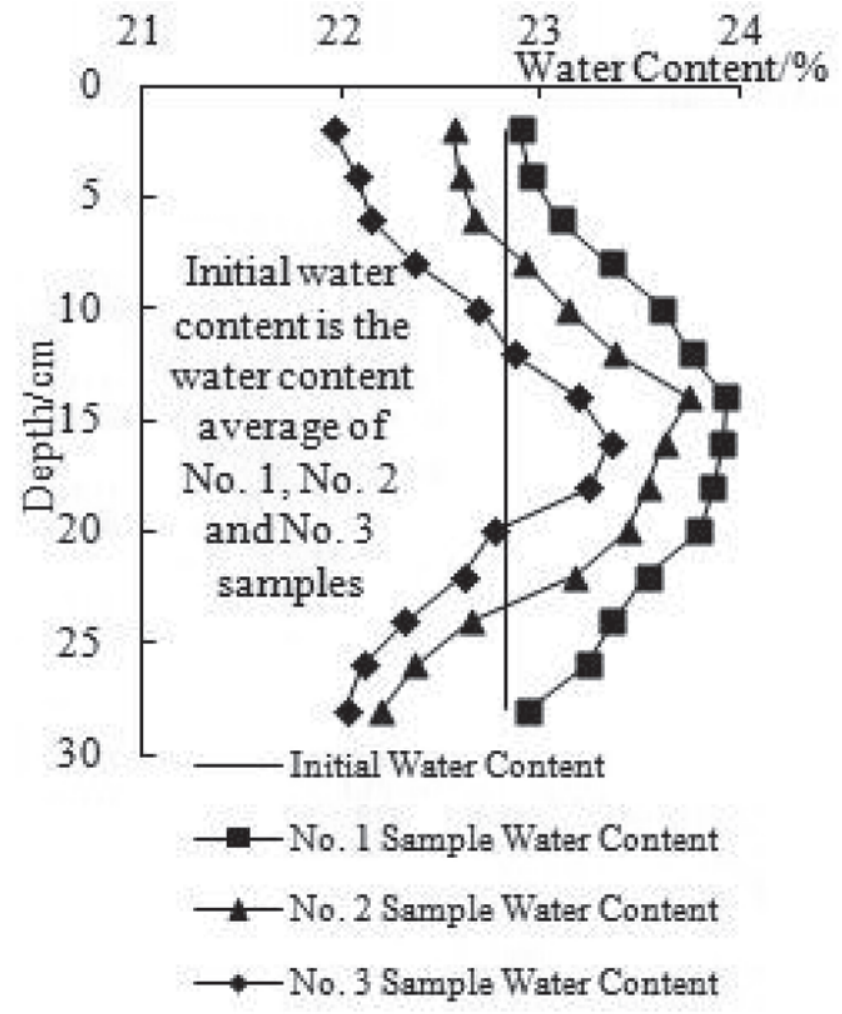

Fig.3 Water content of samples along depth direction of first group soil sample

higher, and so is the water accumulation. The initial water contents of Nos.4, 5 and 6 soil samples at canal bottom were $23.15 \%, 23.79 \%$ and $23.41 \%$, respectively. After thawing, their water contents were increased by $1.78 \%, 2.58 \%$ and $1.86 \%$, respectively. However, for Nos.7, 8 and 9 samples on the sunny slope, the water contents after thawing were increased by $0.95 \%, 1.11 \%$ and $1.14 \%$, respectively, than the initial water contents. Under the same top plate temperature, the samples with similar initial water content has similar water transfer amount. For Nos. 1 and 2 samples on the canal shady slope, 


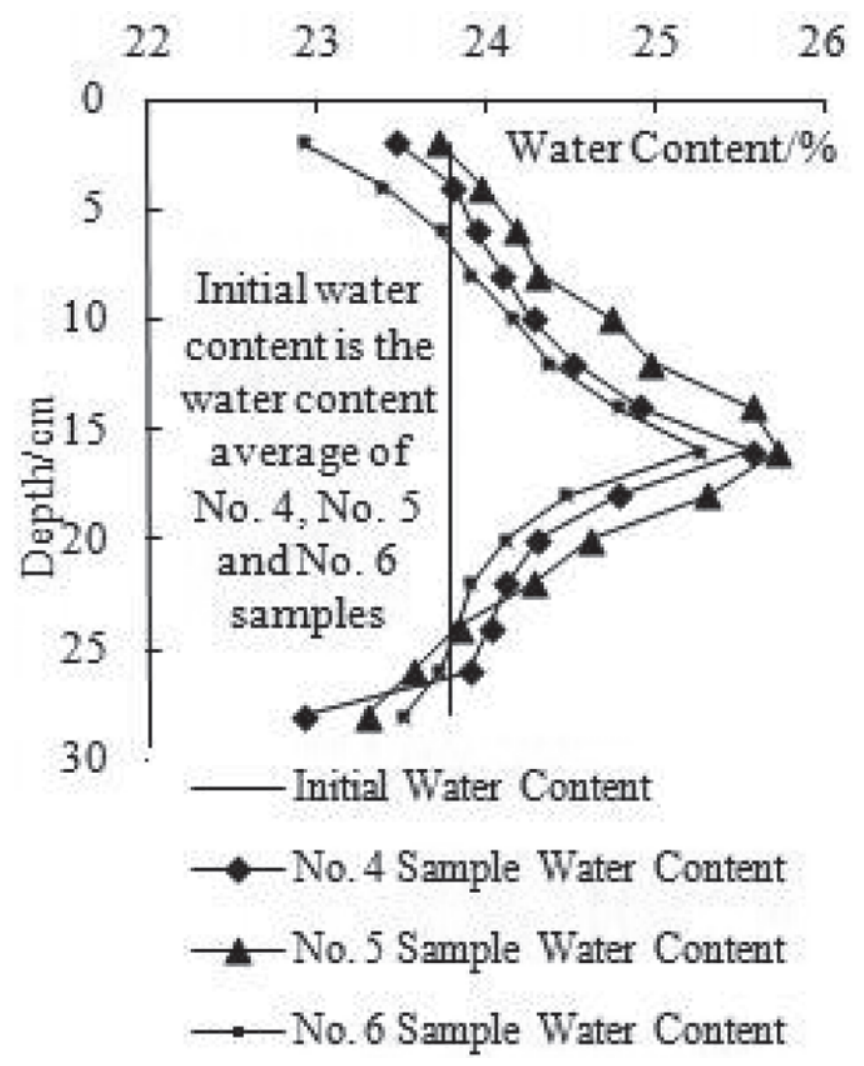

Fig.4 Water content of samples along depth direction of second group soil sample

the initial water contents were $22.67 \%$ and $22.58 \%$, respectively. After thawing, the water contents at the depth of $16 \sim 18 \mathrm{~cm}$ were increased to $23.93 \%$ and $23.74 \%$, with an increase of $1.26 \%$ and $1.16 \%$, respectively, which means water transfer amount only has a little difference.

Comparing the results in Figs.3, 4 and 5, we conclude that various temperature patterns and water contents have significant effects on migration of water in soil samples. When the freezing temperature of soil samples is the same, samples with high water contents tend to gather more water. The initial water content of Group 1 soil samples is $22.83 \%$ in average, and the content increases to $23.93 \%$ at the depth of $16-18 \mathrm{~cm}$ during the freezing period. The initial water content of Group 2 soil samples is $23.78 \%$ in average, and the content goes up to $25.73 \%$ at the depth of $16-18 \mathrm{~cm}$ during the freezing period. The initial water content of Group 3 soil samples is $22.31 \%$ in average, and the content increases to $23.26 \%$ at the depth of $16-18 \mathrm{~cm}$ during the freezing period. Taken together, the results indicate that high water contents make it easy to gather water in soil samples during the freezing period.

From Figs.3, 4 and 5, it can be seen that the characteristics of the water accumulation in the soil depth of $16 \sim 18 \mathrm{~cm}$ is basically the same. This shows, from one aspect, that the variation rule obtained by the soil sample test is basically reliable. Although the scales of the prototype observation

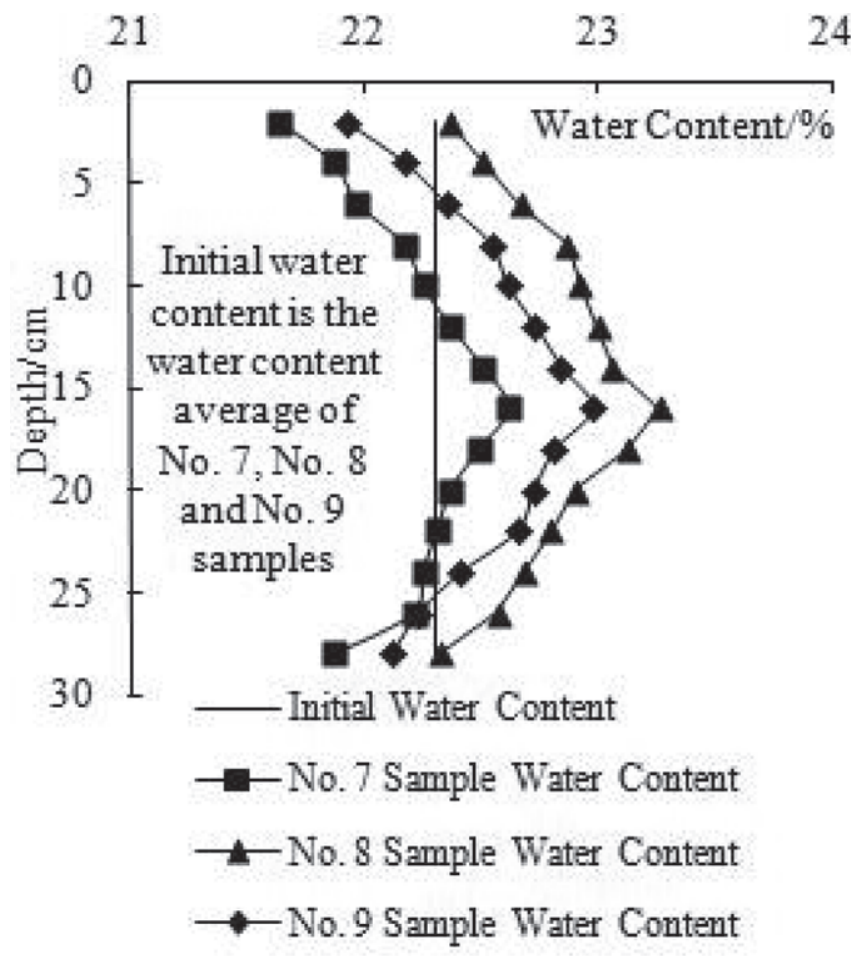

Fig.5 Water content of samples along depth direction of third group soil sample

tests and laboratory soil sample tests are not the same, the water content change rule is the same, which also shows that the results of field prototype observation tests and laboratory soil sample tests can be verified mutually.

\section{Conclusion}

1. The prototype test on water migration in composite lining canal shows that seasonal freeze-thaw process has the function of accumulating upward and reducing downward the soil water in the rigid-flexible mixed composite lining trapezoidal canal foundation. Under the conditions of no groundwater recharge, the water content of the canal foundation soil in the depth of $0 \sim 80 \mathrm{~cm}$ increases with the depth and decreases gradually with the depth in the depth of $80 \sim 160 \mathrm{~cm}$; and the freezing front of the canal foundation soil is formed when water accumulates in the depth of $60 \sim 80 \mathrm{~cm}$. During the freezing period, the maximum water transfer amount in the depth of $60 \sim 80 \mathrm{~cm}$ (where water accumulates) is $+13.2 \%$, which occurs at the bottom of the canal, and wherein the water accumulates upward; during the thawing period, the maximum water transfer amount is $-11.0 \%$, which also occurs at the canal bottom, wherein the water dissipates downward.

2. The laboratory freeze-thaw tests on soil samples show that the variation trend of the water content distribution curves of different soil samples in different positions of the composite lining canal is the same. The water content in the upper soil layer increases, and the water content in 
the lower soil layer decreases, with water accumulating in the depth of $16 \sim 18 \mathrm{~cm}$. Under the same top plate temperature, the sample with higher initial water content will have more water transfer amount, and water accumulation is also higher. Samples with similar initial water content will have similar water transfer amount.

3. Through different scale prototype observations and soil sample freeze-thaw tests in the laboratory, the change rule of canal foundation soil water content in the seasonal freeze-thaw cycles was revealed. The water content by laboratory freeze-thaw tests and prototype tests has the same change rule; however, it is unable to simulate the real water migration situation of the composite lining canal under seasonal freeze-thaw environment. The canal's prototype observation test under seasonal freeze-thaw environment can truly reflect the soil water migration rule. This prototype observation test only studied the change of water content in the depth direction, but the actual situation is more complicated since water may migrate in the horizontal direction. The tests for water transfer amount in the space dimension at the same time have not been conducted yet, which requires further research work.

After analysis the research works up to now, the questions within the researches on the coupled heatmoisture-stress interaction is also presented. Therefore, it is necessary to improve the models in order to reflect the natural and physic properties, to test in fields and to search the methods of measuring the parameters in the models.

\section{Acknowledgements}

This paper belongs to the project of the National Natural Science Foundation of China, No.51269029; the National Natural Science Foundation of China, No.51408377; Shihezi university outstanding youth science and technology talent cultivation plan, No.2015ZRKXJQ06

\section{References}

[1] LI Ping, XU Xue-zhu, XU Feng-feng. (2000): State and Progress of Research on the Frozen Fringe and Frost Heave Prediction Models[J]. Journal of Glaciology and Geocryology, 22(1): 90-95.

[2] Kurylyk B L, Watanable K. (2013): The mathematical representation of freezing and thawing processes in variably-saturated, non-deformable soils [J]. Advances in Water resources, 60: 160-177.

[3] Sheshukov A Y, Nieber J L. (2011): One-dimensional freezing of non heaving unsaturated soils: Model formulation and similarity solution $[\mathrm{J}]$. Water Resources Research, 47(11). doi:10.1029 / 2011Wr010512.

[4] Zeng Gui-yun, Zhang Ming-yi, LI Zhen-ping, et al.
(2015): Study of moisture migration and frost heave model of freezing saturated soil [J]. Rock and Soil Mechanics, 36(4):1085-1092.

[5] Lenoid Bronfenbrener. (2009): The modeling of the freezing process in fine-grained porous media of Application to the frost heave estimation [J]. Cold Regions Science and Technology, 56: 120-134.

[6] Zheng Yun, Ma Wei, Bing Hui. (2015): Impact of freezing and thawing cycles on structure of soils and its mechanism analysis by laboratory testing $[\mathrm{J}]$. Rock and Soil Mechanics, 36(5):1282-1294.

[7] Yin Qi-xiang, Zhou Guo-qing, et al. (2015): Zhao Xiaodong, et al. Experimental study of the water migration and compression of soils under double direction freezing-one direction thawing[J]. Rock and Soil Mechanics, 36(4):1021-1026.

[8] Zhao Gang, Tao Xia-Xin, Liu Bin. (2009): Experimental study on water migration in undisturbed soil during freezing and thawing process $[\mathrm{J}]$. Chinese Journal of Geotechnical Engineering, 31(12):1952-1597.

[9] Song Cun-niu. (2010): A Review on Theory Model about Coupled Heat-Moisture Stress Interaction during Soil Freezing and Thawing[J]. Journal of Glaciology and Geocryology, 32(5):982-988.

[10] Li Xue-Jun, Fei Liang-Jun, Ren Zhi-zhong. (2007): Soil moisture transfer in the base of U-shape canal with concrete lining in the process of seasonal freezing and thawing[J]. Shuili Xuebao, 38(11):1383-1387.

[11] Jing Ji-hong, Han Shuang-ping, Wang Xin-zhong. et al. (2007): The Mechanism of Water Movement in the Freeze-thaw Process[J]. Acta Geoscientica Sinica, 28(1):50-54.

[12] Thomas H R, Cleall P, Li Y C, et al. (2009): Modelling of cryogenic processes in perma-frost and seasonally frozen soils[J]. Geo-technique, 59(3): 173-184.

[13] Zhou Jia-Zuo, Li Dong-Qing. (2012): Numerical analysis of coupled water, heat and stress in saturated freezing soil[J]. Cold Regions Science and Technology, 72:43-49

[14] Klinova G, Aksenov V, Dzhakhan Girova N. (2010): Thaw-induced deformation properties of frozen soils[J]. Soil Mechanics and Foundation Engineering, 47(3): 102-107.

[15] Shafique U, Anwar J, Uz-Zaman W, et al. (2012): Forced migration of soluble and suspended materials by freezing front in aqueous systems[J]. Journal of Hydro-Environment Research, 6(3): 221-226

[16] Lai Y, Xu X, Dong Y, et al. (2013): Present situation and prospect of mechanical research on frozen soils in China[J]. Cold Regions Science and Technology, 87(1):6-18 
[17] Kang Y, Liu Q, Huang S. (2013): A fully coupled thermo-hydromechanical model for rock mass under freezing/thawing condition[J]. Cold Regions Science and Technology, 95(1):19-26.

[18] Wang Zheng Zhong. (2008): Establishment and application of mechanics model of frost heaving damage of concrete lining trapezoidal open canal [J]. Transactions of the Chinese Society of Agricultural Engineering, 20(3):24-29.

[19] Shi Jiao, Wang Zheng Zhong, Zhang Feng li, et al. (2015): Development and application of frost-heaving fracture damage mechanical model for concrete lining channel with arc-bottom trapezoidal at high groundwater level [J]. Journal of Northwest $A \& F$ University Nat. Sci. E, 43(1):213-219.

[20] An Peng, Xing Yi chuan, Zhang Ai jun, et al. (2013):
Study of design method and numerical simulation for anti-frost heave cushion of canal [J]. Rock and Soil Mechanics, 34 (Supp.2): 257-271.

[21] Experimental study on freezing temperature and salt crystal precipitation of sodium sulfate solution and sodium sulfate saline soil [J]. Chinese Journal of Geotechnical Engineering, 2013, 35(11): 2090-2096.

[22] LI Shun-Qun, Gao Ling-Xia, Chai Shou-xi. (2012): Significance and interaction of factors on mechanical properties of frozen soil [J]. Rock and Soil Mechanics, 33(4):1174-1176.

[23] Tan Long, Wei Chang-Fu, Tian Hui-hui, et al. (2015): Experimental study of unfrozen water content of frozen soils by low-field nuclear magnetic resonance[J]. Rock and Soil Mechanics, 36(6): 15661572 .

\section{RESEARCH ON THE DECISION OF STATE MAINTENANCE FOR TRANSMISSION LINE BASED ON SET PAIR ANALYSIS}

(Continued from page 23)

\section{References}

1. Han D. J., White A. (1995): Transformer Design for High Reliability $[\mathrm{J}]$. The reliability of transmission and distribution equipment, (406): 29-31.

2. Van Schijndel A., Wetzer J. M. (2006): Forecasting Transformer Reliability [J]. IEEE conference on electrical insulation and dielectric phenomena, 577-582.

3. Md. Mafijul Islam Bhuiyan, Petr Musilek, et al. (2010): Evaluating Thermal Aging Characteristics of Electric Power Transmission Lines [J]. Electrical and computer engineering (CCECE), 2010 23rd Canadian Conference, 1-4.

4. Aggarwal R. K., Johns A. T., Jayasinghe J.A.S.B. (2000):
An Overview of Thecondition Monitoring of Overhead Line [J]. Electric power system research, 6:22.

5. Harly W., Sokolov J. (2000): Contribution of Panel on Modern Maintenance Techniques for Enhancing the Reliability of Insulation of Power Transmission Systems. CIGRE-Report Pi-06, 87-91.

6. Wang H., Phara H. (1999): Some Maintenance Models and Availability with Imperfect Maintenance in Production Systems [J]. Annals of operations research, 91(3): 306.

7. GuoWeiyue. (2006): Preventing Measures of Bird Interference with Transmission Lines and Substation Equipment in U. S [J]. Electric Power, 39(8): 82-84.

\section{Indian Journal of Power \& River Valley Development Please renew your subscription}

For details, contact : e-mail: bnjournals@gmail.com

Printed by Pradip Kumar Chanda at The Indian Press Pvt. Ltd. 93A Lenin Sarani, Kolkata 700013 and published by him for Books \& Journals Pvt. Ltd. from 62 Lenin Sarani, Kolkata 700013 